\title{
PULSATILE DRUG DELIVERY SYSTEMS: A CASE OF BETA-BLOCKERS
}

\author{
ALANKAR SHRIVASTAVA* \\ Department of Pharmaceutical Quality Assurance, KIET School of Pharmacy, Ghaziabad-Meerut Road (NH-58) Muradnagar-201206, \\ District Ghaziabad. Email: alankar.shrivastava@kiet.edu
}

Received: 12 September 2018, Revised and Accepted: 30 November 2018

\section{ABSTRACT}

The diseases involve heart and blood vessels are classified under cardiovascular diseases. Hypertension (HTN) is a disorder of the CV system characterized by elevated arterial blood pressure. Pulsatile drug delivery systems are on highlight today. This is due to their distinct advantage of releasing drug as the circadian rhythm of the disease. The beta-blockers are first-line therapy for the HTN. Hence, researches related to such modified formulations of these drugs are of need to increase the patient compliance and convenience. This review describes the various such systems published in literature. This also includes a brief description about circadian rhythm and beta-blockers. The researchers involved in the development of modified release formulations are the main target audience for this review.

Keywords: Pulsatile drug delivery system, Hypertension, Cardiovascular disease, Circadian rhythm, $\beta$-Blockers.

(c) 2019 The Authors. Published by Innovare Academic Sciences Pvt Ltd. This is an open access article under the CC BY license (http://creativecommons. org/licenses/by/4. 0/) DOI: http://dx.doi.org/10.22159/ajpcr.2019.v12i3.29704

\section{INTRODUCTION}

Cardiovascular diseases (CVD) are the leading cause of death globally, representing $\sim 30 \%$ of all mortality [1]. Hypertension (HTN), as the sole or comorbid component of a constellation of disorders of the $\mathrm{CV}$ system, is present in over 90\% of all patients with CVD and affects nearly 74 million individuals in the United States [2].

HTN remains the leading cause of CV morbidity and mortality, including stroke, heart disease, kidney disease, and other vascular disease. The relationship between blood pressure (BP) and CV risk is linear, continuous, and additive to other well-known risk factors such as diabetes, dyslipidemia, obesity, and cigarette smoking [3]. In the majority of cases, HTN is thought to result from an interaction of genes with environmental factors [4].

HTN is a disorder of the CV system characterized by elevated arterial BP. The BP in the arteries is dependent on the energy of cardiac contractions, elasticity, and contractile state of arterial walls, as well as on the volume and viscosity of the blood. It fluctuates with every heartbeat [5].

The higher the BP elevation, the greater the likelihood that various CV complications will ensue. If untreated, about $50 \%$ of hypertensive patients die of coronary heart disease or congestive heart failure (HF), about $33 \%$ die of stroke, and $10-15 \%$ die of renal failure [6]. HTN is classified as essential (primary) or secondary to, for example, a renal parenchymal, renovascular or an endocrine disorder [7].

In industrialized countries, the risk of becoming hypertensive (BP $>140 / 90 \mathrm{mmHg}$ ) during a lifetime exceeds 90\%. Essential HTN usually clusters with other $\mathrm{CV}$ risk factors such as aging, being overweight, insulin resistance, diabetes, and hyperlipidemia. Most hypertensive patients need two or more drugs for blood-pressure control and concomitant statin treatment for risk factor reduction. Despite the availability of effective and safe antihypertensive drugs, HTN and its concomitant risk factors remain uncontrolled in most patients [8].

Circadian rhythms are defined as those rhythms that are endogenously generated, have a periodicity of approximately $24 \mathrm{~h}$ and whose rhythmicity persists when environmental conditions (light, temperature, posture, etc.) are kept constant [9]. In humans, many aspects of human physiology and behavior vary with circadian phase. Circadian rhythms are self-sustained and persist in the absence of environmental time cues with remarkable precision [10]. The biological clock drives all circadian rhythms in humans, whether relative to neurobehavioral function, hormones, physiology, or behavior [11].

The mammalian circadian system is organized in a hierarchy of oscillators. At the top of this hierarchy is the suprachiasmatic nucleus (SCN) of the anterior hypothalamus. The SCN is responsible for coordinating independent peripheral oscillators so that a coherent rhythm is orchestrated at the organismal level [12]. SCN is a cluster of nerve cells located in the brain region called the hypothalamus that is responsible for generating and coordinating circadian rhythmicity in mammals [13].

The SCN that are synchronized to solar time by direct retinal afferents. Individual SCN neurons are circadian clocks, their intrinsic oscillator consisting of a series of interlinked autoregulatory transcriptional/ post-translational feedback loops [14].

The humans exhibit circadian rhythms in hormone concentration (e.g., melatonin, varying between $\sim 0$ and $50 \mathrm{pM}$; cortisol, varying between $\sim 100$ and $400 \mathrm{nM}$ ), plasma lipid concentration, core body temperature, plasma glucose concentrations, heart rate, autonomic nervous system activity, $\mathrm{BP}$, subjective alertness, and objective reaction time, independent of the sleep/wake, and fasting/feeding cycles [15].

CVD, diabetes, and obesity affect millions of people worldwide, and the rates of these cardiometabolic diseases are on the rise. Circadian misalignment results are as follows (Figs. 1 and 2):

- Impaired glucose tolerance as a result of decreased insulin sensitivity and inadequate beta cell response

- Elevated inflammatory markers

- Elevated mean arterial pressure

- Decreased energy expenditure [16].

Despite the recent and substantial advances in the treatment of HTN, the majority of patients still remains not optimally controlled; hence, the 


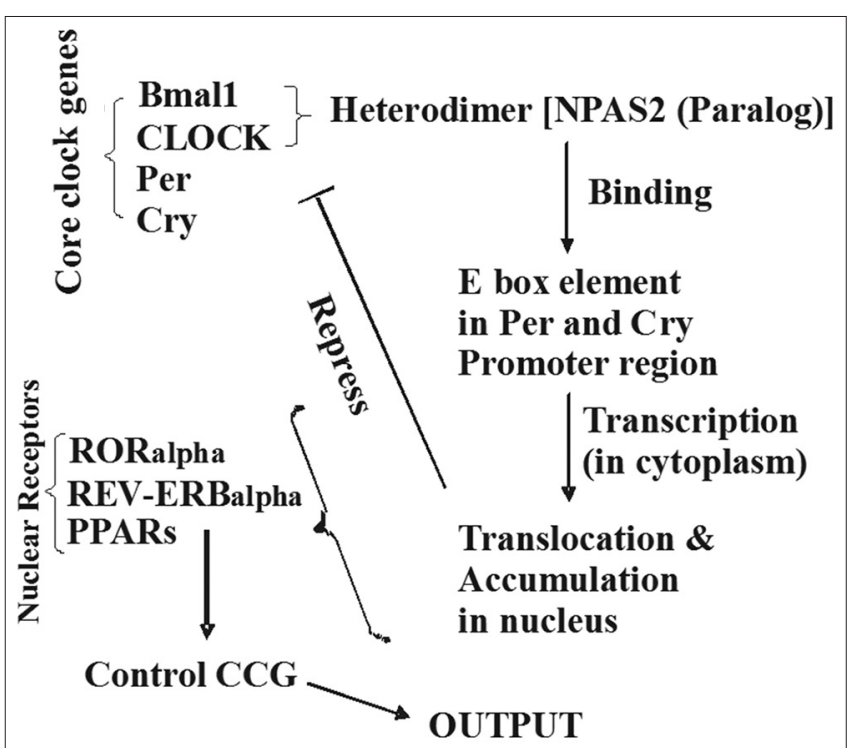

Fig. 1: Circadian rhythm

need for innovative strategies to lower BP [17]. Traditional treatments, as well as many new approaches to HF, appear to have little impact on the risk of clinical progression or mortality [18].

$\beta$-blockers have been used widely since the 1970s in the treatment of HTN [19]. The use of beta-blockers ( $\beta$-blockers) in clinical practice has been evolving for more than half a century. At present, these medications are used for a number of medical conditions such as unstable angina, acute myocardial infarction, HF, HTN, atrial fibrillation, ventricular arrhythmias, migraine headache, hyperthyroidism, essential tremor, aortic dissection, social phobia, glaucoma, esophageal varices, and so on [20].

In humans, at least three types of beta-receptor exist ( $\beta 1, \beta 2$, and $\beta 3)$ and these are an integral part of the sympathetic nervous system. In the heart, $\beta 1$ - and $\beta 2$-receptors are found in the sinoatrial and atrioventricular nodes and myocardium. Norepinephrine release from sympathetic nerve fibers stimulates beta-receptors causing heart rate and contractility to increase. Renin release from the kidney is also mediated by $\beta 1$-receptors, linking activation of the sympathetic nervous and renin-angiotensin systems. $\beta 2$-receptors are found in the smooth muscle of venules and arterioles and stimulation of these receptors leads to vasodilatation [21].

Beta-blockers block the action of endogenous catecholamines on betaadrenergic receptors. There are three known receptor types: $\beta-1,2$, and 3. $\beta-1$ adrenergic receptors are located in the heart and kidneys; $\beta-2$ receptors are in the pancreas, liver, fat, uterus, vascular smooth muscle, and skeletal muscle; and $\beta-3$ receptors are found in the fat. The non-selective drugs such as propranolol and labetolol, blocks all beta receptors. $\beta-1$ selective agents, metoprolol, and bisoprolol act only on the heart. $\beta$-blockers act by decreasing heart rate and contractility, thereby balancing myocardial supply and demand and reduce cardiac events. $\beta$-blockers are also thought to stabilize coronary plaque, inhibit renin release, and increase the threshold for tachyarrhythmias [22].

Traditional $\beta$-blockers - propranolol, atenolol, metoprolol, acebutolol, bisoprolol, betaxolol, penbutolol, nadolol, pindolol, and timolol are the most recommended and commonly used $\beta$-blockers for treatment of HTN. Combined $\alpha / \beta$-blockers such as carvedilol, nebivolol, and labetalol can reduce BP by reducing systemic vascular resistance rather than by decreasing cardiac output, as is observed with regular $\beta$-blockers, yet not have the same vascular and metabolic effects as atenolol or metoprolol [23].

\section{PULSATILE DRUG DELIVERY SYSTEMS}

Oral pulsatile drug delivery systems are designed for application at the optimal time against diseases that occur depending on circadian rhythm. Most of the pulsatile drug delivery systems are reservoir systems with a barrier layer. The barrier can be dissolved or eroded after a predetermining lag time, and the drug is released outside from reservoir system [24].

With the advancement in medical science and understanding the importance of biodistribution and pharmacokinetics of therapeutic agents, modern drug delivery research strives to utilize novel materials and fabrication technologies for the preparation of robust drug delivery systems to combat acute and chronic diseases [25].

Pulsatile drug delivery systems are gaining a lot of interest in the field of modified release drug delivery systems. These systems constitute a relatively new class of devices, the importance of which is especially connected with the recent advances in chronopharmacology [26].

There are many conditions and diseases where sustained release formulations do not show good efficiency such conditions demand the release of drug after a lag time, i.e., form of pulse [27]. The pulsatile delivery system is also known as time controlled release system as it is independent of $\mathrm{pH}$, enzymes, gastrointestinal motility, etc. [28].

\section{Propranolol}

Propranolol is a nonselective, competitive antagonist at betaadrenoceptors. It binds with high affinity to both beta- 1 and beta- 2 receptor subtypes but has lower affinity at the beta-3 subtype. Although propranolol is rapidly absorbed following oral administration, it has a relatively low bioavailability due to significant first-pass metabolism. Propranolol is highly bound to plasma proteins and eliminated by hepatic metabolism [29].

Side effects of propranolol are rare but may include bradycardia, hypotension, and hypoglycemia. Other potential side effects include bronchospasm, fatigue, nightmares, HF, and peripheral vasoconstriction [30].

There are two pulsatile systems found in literature. The first one [31] is developed with minimization of transit time and $\mathrm{pH}$ effects of the gastrointestinal tract. The formulation compositions for matrix pellets prepared by an extrusion-spheronization method with the addition of either $\mathrm{NaCl}$ as osmogent and solubility modifier or lactose as osmogent using Eudragit (plasticized with 30\% Triethyl citrate) as the controlling membrane.

The study by Newton et al. [32] has been designed to develop a delayed release matrix tablets using various natural polymers. The Carbopol 940 was used as an auxiliary polymer to modify the drug release and to improve the compression characteristics in high-speed tablet compression machines. The in vitro studies were performed in developed matrix system in $0.1 \mathrm{~N} \mathrm{HCl}$ for $1.5-2 \mathrm{~h}$ and in $\mathrm{pH} 6.8$ phosphate buffer for $2 \mathrm{~h}$ and after that $\mathrm{pH} 7.4$ buffer until the maximum amount of drug release.

\section{Metoprolol}

Metoprolol is a cardioselective beta-adrenoceptor antagonist. It has a higher affinity for $\beta 1$-receptors than for the $\beta 2$-receptor subtype. Receptor subtype selectivity is diminished at higher doses. Metoprolol and other beta-adrenoceptor antagonists are used widely to treat CVD, including HTN, angina, arrhythmias, myocardial infarction, and congestive HF [33].

A core in cup (three component tablet) is prepared wherein core tablet, an impermeable material surrounding the tablet except the top and soluble hydrophilic polymer layer at the top is designed. The core tablet contains metoprolol tartrate, cellulose acetate propionate is used as impermeable membrane and sodium alginate $500 \mathrm{cps}$ and sodium 


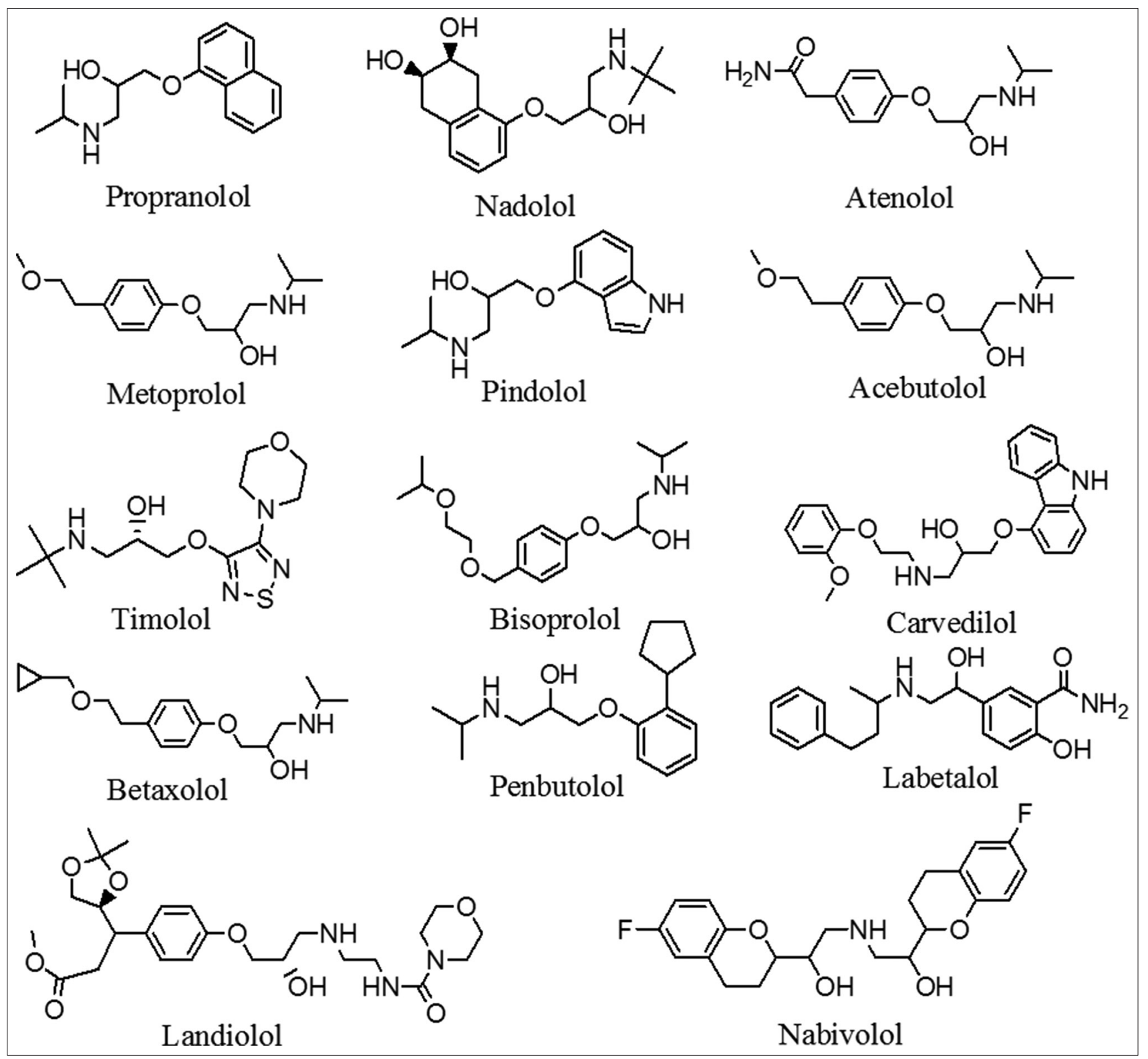

Fig. 2: Beta-blockers

alginate 2000 cps used as a soluble hydrophilic polymer layer. The concentration of the top layer of hydrophilic polymer is a critical factor governing the release pattern, increase in the concentration increased lag time and delay the release [34].

Another pulsatile delivery system in which core tablets were prepared using various concentrations of super disintegrates, the formulated core tablets were coated with the polymers using compression coating technology. Three different formulations were prepared with varying concentrations of hydroxypropyl methylcellulose. The first formulation showed maximum drug release after $3 \mathrm{~h}$ and another two after the $8^{\text {th }} \mathrm{h}[35]$.

In another study, a swellable tablet with Eudragit was prepared for the timed control release. To study the influence of the formulation factors (amount of coating polymer, plasticizer percentage in film coating, and swelling agent percentage in mini-tablets), a Box-Behnken design of experiment was used. The lag phase of 2.5-h followed by rapid drug release was obtained [36].

The study conducted by Emami and Kazemali [37] presented core tablets contained metoprolol, sodium chloride, lactose, Avicel, and starch. Powders were mixed, sieved, and directly compressed into tablets using a single punch tablet machine. Core tablets were then coated with 5 or $10 \%$ hydroxypropyl methylcellulose as a swelling layer and subsequently outer membrane with the mixture of various ratios of Eudragit at different coating levels 5, 10, and 15\% as semi-permeable water insoluble outer coat by the conventional pan-spray method.

Another floating pulsatile delivery system consisted of three different parts: A core tablet, containing the active ingredient, an erodible outer shell, and a top cover buoyant layer. The rapid release core tablet (RRCT) was prepared using superdisintegrants along with active ingredient. Dry coating of optimized RRCT was done using different grades of hydroxypropyl methylcellulose (HPMC), and uppermost buoyant layer was prepared with HPMC and sodium bicarbonate. The optimized floating pulsatile release tablets (FPRT) formulation showed floating lag time of $4 \mathrm{~min}$, floating time of $12 \mathrm{~h}$ and release lag time of $6 \mathrm{~h} \mathrm{[38].}$

Similarly, formulation consists of press-coated optimized RRCT were developed using different ratios of HPMC and Ethylcellulose. The swelling layer is composed of croscarmellose sodium, a super disintegrant and microcrystalline cellulose (MCC) as a diluent, while the rupturable coating is Ethylcellulose [39]. 
Pulsatile system with lag time of $6 \mathrm{~h}$ in onset of drug release in vitro followed by sustained drug release over a period of $12 \mathrm{~h}$ developed by Agrawal et al. [40]. Optimization of different grades of hydroxypropyl cellulose (HPC) polymer concentrations in the outer coat of tablets such that the optimized formulation contained low substituted HPC (L-HPC) and HPC-M in the ratio of 1:2. The optimized formulation produced a lag phase of $6 \mathrm{~h}$ followed by a complete release of $99.02 \pm 0.82 \%$ in $12 \mathrm{~h}$

Taranalli et al. [41] developed hollow calcium pectinate beads for floating pulsatile release of metoprolol tartrate intended for chronopharmacotherapy. Floating pulsatile concept was applied to increase the gastric residence of the dosage form having lag phase followed by a burst release. The floating beads obtained were porous, float up to $12-24 \mathrm{~h}$. All formulations followed first-order release kinetics by a diffusion mechanism.

\section{Carvedilol}

Carvedilol is a non-cardioselective beta-blocker used in the treatment of HTN and angina pectoris [42]. The addition of chronotherapy with carvedilol may be an effective way to suppress morning surges of HTN [43]. Carvedilol is a drug showing antioxidant properties used in clinical practice for the treatment of CVD (HTN, congestive HF, or myocardial infarction). The oral bioavailability remains low (e.g., 23\%) due to significant first-pass hepatic metabolism by cytochrome P450 and also has a short plasma half-life [44].

Compression coated tablet [45] containing carvedilol phosphate in the core was formulated with an outer coat by Eudragit and Ethylcellulose. A numerical optimization technique was adopted to achieve optimized formulation. The system was formulated into two steps: First, core tablet was prepared containing a drug; and second, core tablet was coated with a polymer blend of Eudragit (enteric polymer) and Ethylcellulose (water-insoluble polymer).

Rupturable pulsatile drug delivery system [46] consists of a drug core; swelling layer of a super disintegrant; and an insoluble, water permeable polymeric coating. On water ingress, the swellable layer expands, resulting in the rupturing of the outer membrane followed by drug release. The drug was deposited on sugar pellets as the first layer and the second layer composed of the swelling layer composed of swelling excipients, had crospovidone, HPC-L, and sodium starch glycollate. The outermost layer was composed of Ethylcellulose.

Core tablets $(6 \mathrm{~mm})$ containing carvedilol and $10-\mathrm{mm}$ press-coated tablets were prepared [47] by direct compression using different concentrations of rate-controlling polymers. Hydroxypropyl methylcellulose, Ethylcellulose, and K-carrageenan were used as rate-controlling polymers in the outer layer. The varying lag time and percent cumulative carvedilol release after $8 \mathrm{~h}$ was optimized to obtain a formulation that offered a release profile with $6 \mathrm{~h}$ lag time followed by complete carvedilol release after $8 \mathrm{~h}$.

Another chronotherapeutic delivery of carvedilol containing biodegradable polymers coated with $\mathrm{pH}$ sensitive polymers developed by Patel and Dhake [48]. Chitosan was used as a carrier for drug delivery, and Eudragit $\mathrm{S} 100$ was used as an enteric coating polymer. The chitosan microspheres were prepared by emulsion cross-linking method with an average particle size of microsphere formulations in the range of 9.93 $\mu \mathrm{m}-18.48 \mu \mathrm{m}$. Within $5 \mathrm{~h} 70-90 \%$ of the drug was released.

Rupturable pulsatile mini-tablet consists of a drug core; swelling layer of a super disintegrant; an insoluble, water-permeable polymeric, and enteric coating. On water access, the swellable layer expands, resulting in the rupturing of the outer membrane followed by drug release. There was no drug released in the acid phase. The second layer composed of swelling excipient had crospovidone, croscarmellose sodium, and sodium starch glycolate. Third and the outer most layer was based on Ethylcellulose and an enteric polymer [49].

\section{Bisoprolol}

Bisoprolol fumarate possesses an asymmetric carbon atom in its structure and is provided as a racemic mixture [50]. Bisoprolol is the most selective among the other second-generation $\beta$-blockers such as metoprolol and atenolol [51]. The $\beta$-blocker bisoprolol was approved by the FDA as an antihypertensive agent for clinical use in 1992. The $\mathrm{S}(-)$-enantiomer of bisoprolol possesses 15 - to 40 -times greater activity than the $\mathrm{R}(+)$-enantiomer, thus, it is the most pharmacologically active [52].

Compression coated floating pulsatile drug delivery systems were developed by the Jagdale et al. [53] The prepared system consisted of two parts: A core tablet containing the active ingredient and an erodible outer shell with a gas generating agent. The inner core tablets were prepared by mixtures of bisoprolol fumarate, MCC, croscarmellose sodium, and lactose dry blended for 20 min followed by addition of magnesium stearate. FPRT were prepared by press coated method using polyethylene oxide. Sodium bicarbonate and citric acid were used as a gas generating agent.

\section{Atenolol}

Atenolol is a $\beta 1$-receptor antagonist that is widely used in the therapy of diverse CVD such as angina pectoris, cardiac arrhythmia, and systematic HTN [54]. In atenolol, the stereogenic center resides at the $\mathrm{N}$-N-dimethyl propoxy side chain, resulting in the existence of enantiomeric pair. S-Atenolol is the S-enantiomer of $( \pm)$-atenolol, the eutomer, which alone is responsible for the $\beta$-adrenoceptor blocking activity [55]. The S-enantiomer has been found to lack the reported side effect of a lowered heart rate sometimes encountered with the racemate [56].

Pulsatile release tablet comprises a drug containing core and pH-sensitive polymeric coating (Eudragit S-100, Ethylcellulose, and sodium alginate). In this system, MCC was used as the direct compressing agent. Crospovidone was used as disintegrating agents. Magnesium stearate and Talc were used as lubricants [57].

Another pulsatile formulation of atenolol was developed by Keraliya and Patel [58]. In this core, tablet consists of drug and coated with varying viscosity of HPC. With this two formulations with a lag phase of 6 and $6.5 \mathrm{~h}$ were prepared. The core tablet was prepared by mixing the drug with MCC, sodium starch glycollate, polyvinyl pyrrolidone (PVP), talc, and magnesium stearate. Followed by a coating of HPC was performed and formulation was optimized for the desired lag time.

The pulsatile delivery developed by Bonthagarala et al. [59] developed RRCT using superdisintegrants along with active ingredient atenolol. Press coating of optimized RRCT was done using different ratios of HPMC and Ethylcellulose. This system consists of a core tablet coated with two layers, an inner swelling layer and an outer rupturable coating. The swelling layer is composed of croscarmellose sodium, a super disintegrant and MCC as a diluent, while the rupturable coating is Ethylcellulose.

Another system Jagdale et al. [60] was generated which consisted of three different parts: A core tablet, containing the active ingredient; an erodible outer shell; and a top cover buoyant layer. The dry, coated tablet consists of a drug-containing core, coated by a hydrophilic erodible polymer responsible for a lag phase in the onset of pulsatile release. The buoyant layer, prepared with hydroxypropyl methylcellulose (HPMC), citric acid, and sodium bicarbonate, provides buoyancy to increase the retention of the oral dosage form in the stomach.

\section{Nebivolol}

Nebivolol is a third-generation $\beta 1$-adrenoreceptor antagonist. Unlike other drugs in the same type, it blocks $\beta 1$-adrenoreceptors selectively. It is used a single daily dose. Nebivolol is metabolized in the liver and excreted through the kidneys [61]. 
Table 1: Various developed pulsatile drug delivery systems of beta-blockers

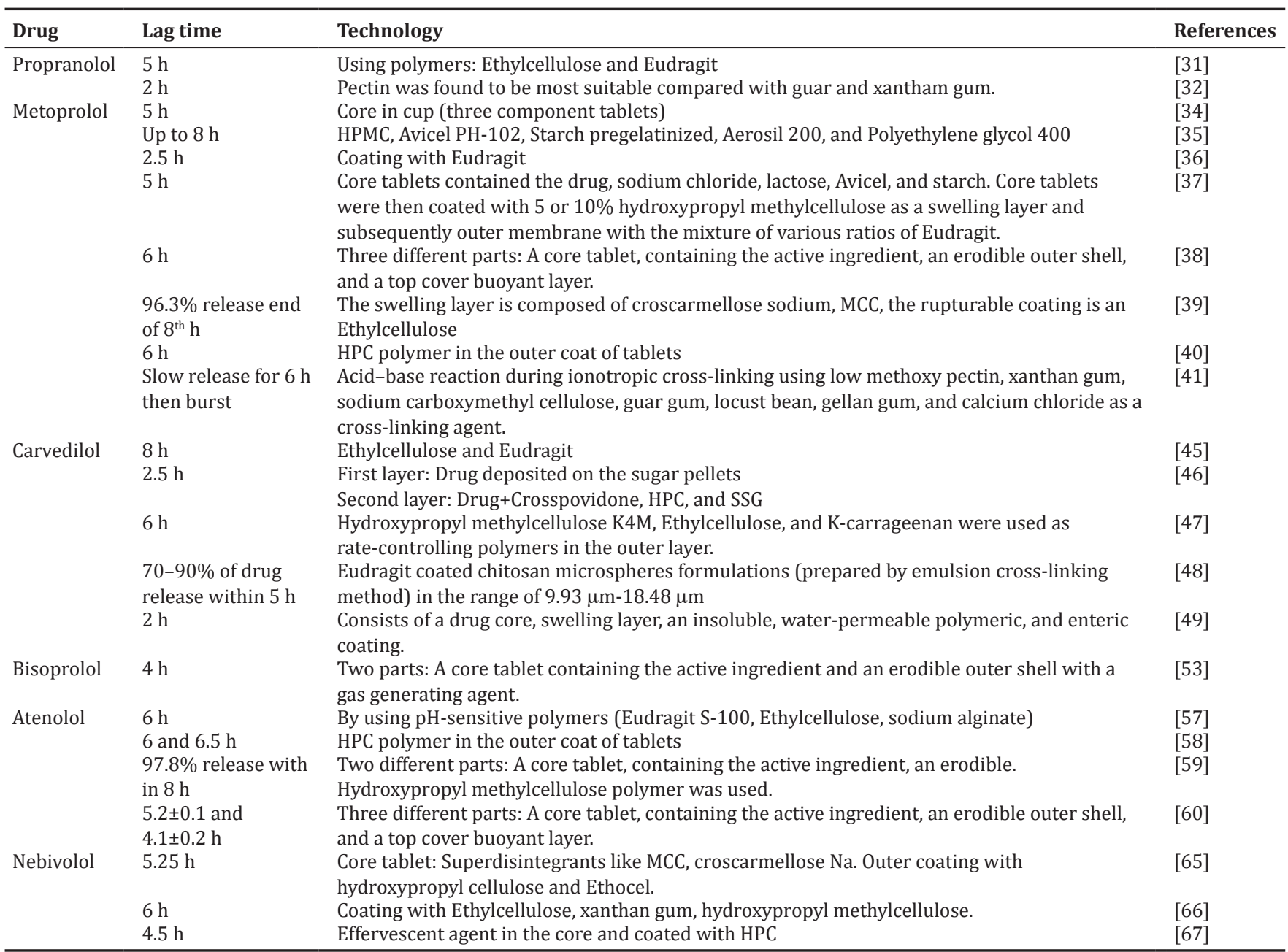

HPMC: Hydroxypropyl methylcellulose, MCC: Microcrystalline cellulose, HPC: Hydroxypropyl cellulose

Nebivolol is a selective $\beta 1$-blocker with a nitric oxide potentiating vasodilatory effect in comparison with other beta-blockers. Nebivolol has a direct stimulatory effect on endothelial nitric oxide synthase, which results in increased levels of local nitric oxide [62]. Nebivolol is used clinically for the treatment of HTN and chronic HF. The recommended dosage to relieve $\mathrm{HTN}$ is $5 \mathrm{mg}$ /day as it shows the best cardioselectivity at such dosage [63]. The BP lowering effect is linked to a reduction in peripheral resistance and an increase in a stroke volume and preservation of cardiac volume [64].

Press coated pulsatile release tablets of nebivolol $\mathrm{HCl}$ developed by Nayak et al. [65] using an admixture of hydrophilic polymer, i.e., L-HPC and hydrophobic polymer, i.e., Ethylcellulose to achieve a predetermined lag time. The core tablet is prepared using superdisintegrants such as MCC and croscarmellose sodium. The press-coated pulsatile tablets containing nebivolol $\mathrm{HCl}$ in the inner core were prepared by compression coating with L-HPC and Ethylcellulose as the outer layer in different ratios.

Another system developed by Sandhya and Jagathi [66] using Ethylcellulose, xanthan gum, HPMC with lag phase of $6 \mathrm{~h}$. The core tablet contains the drug and then coated with polymers such as xanthan gum, HPMC, and Ethylcellulose in varying proportions. After optimization, the selected formulation drug release was $99 \%$ at the end of $12 \mathrm{~h}$. The core tablet was prepared using drug, Avicel, crospovidone, PVP, talc, and aerosol.

The system consisted of a core tablet coated with versatile and safe hydrophilic cellulosic ethers such as hydroxypropyl methylcellulose,
HPC, and sodium carboxymethylcellulose was developed by Shivakumar et al. [67]. From the release profiles depicted in batch can be selected as optimized as it produced a lag time of $4.5 \mathrm{~h}$ with $96.51 \%$ drug release in $8 \mathrm{~h}$.

\section{FUTURE TRENDS}

A total of 23 different pulsatile release formulations found in literature. They all are described in Table 1. These kind of formulations have a distinct advantage as compared to the conventional dosage form as the drug is released according to the circadian rhythm of the disease. Beta-blockers are first-line therapy for the HTN so the development of such modified release formulation will increase the patient compliance without any doubt. Such formulations also require skills during the development phase, and the major disadvantage is the limited dose can be incorporated due to the increase in mass due to polymers and other excipients. Thus, pulsatile release formulations of the drugs with high potency and lesser dose can be prepared. In the case of betablockers, the bisoprolol is available in the form of 5 and $10 \mathrm{mg}$ dosage formulations. This opens a new area of research for the research. Most of such formulations have been found for metoprolol, but the other beta-blockers such as atenolol and nebivolol also open the door for more research in this field.

\section{CONCLUSION}

Modern lifestyle factors are responsible for a growing burden of HTN: Physical inactivity, salt-rich diets with processed and fatty foods, and alcohol and tobacco use [68]. HTN can strain the heart, damage 
blood vessels, and increase the risk of heart attack, stroke, kidney problems, and death [69]. Pulsatile drug delivery systems are gaining importance these days due to convenient and increase in patient compliance. They release of the drug is according to the circadian rhythm of the disease. Here, in this review, various such systems of betablockers are discussed. This review is useful in the development of any such system irrespective of the disease for which it has been opt to. This review is also helpful for the researchers engaged in the development of modified release formulations particularly beta-blockers.

\section{AUTHOR'S CONTRIBUTIONS}

Dr. Alankar Shrivastava is the only author of this paper.

\section{CONFLICTS OF INTEREST}

The author declares that they have no conflicts of interest.

\section{REFERENCES}

1. Coons JC, Empey P. Drug Metabolism in Cardiovascular Disease. Drug Metabolism in Diseases. Philadelphia, PA: Elsevier Inc.; 2017. p. 139.

2. Taylor DA, Abdel-Rahman AA. Novel strategies and targets for the management of hypertension. Adv Pharmacol 2009;57:291-345.

3. Huan Y, Townsend RR. Evaluation and Management of Hypertension. St. Louis, MO: Elsevier; 2014. p. 590-600.

4. Yagil C, Yagil Y. The genomics of hypertension. In: Ginsburg G, Willard H, editors. Essentials of Genomic and Personalized Medicine. New York: Elsevier Inc.; 2010. p. 259.

5. Scriabine A. Hypertension. In: Comprehensive Medicinal Chemistry II. Vol. 6. Oxford, UK: Elsevier Ltd.; 2007. p. 705.

6. Bunag R. Essential Hypertension. xPharm: The Comprehensive Pharmacology Reference. Amsterdam: Elsevier Inc.; 2007. p. 1-6.

7. Bagga A, Jain R, Vijayakumar M, Kanitkar M, Ali U. Evaluation and management of hypertension. Indian Pediatr 2007;44:103-21.

8. Messerli FH, Williams B, Ritz E. Essential hypertension. Lancet 2007;370:591-603.

9. Skene DJ, Arendt J. Human circadian rhythms: Physiological and therapeutic relevance of light and melatonin. Ann Clin Biochem 2006;43:344-53.

10. Czeisler CA, Gooley JJ. Sleep and circadian rhythms in humans. Cold Spring Harb Symp Quant Biol 2007;72:579-97.

11. Wirz-Justice A. How to measure circadian rhythms in humans. Medicographia 2007;29:84-90.

12. Ko CH, Takahashi JS. Molecular components of the mammalian circadian clock. Hum Mol Genet 2006;15 Spec No 2:R271-7.

13. Vitaterna MH, Takahashi JS, Turek FW. Overview of Circadian Rhythms. Available from: https://www.pubs.niaaa.nih.gov/publications/arh25-2/8593.htm.

14. Hastings M, O’Neill JS, Maywood ES. Circadian clocks: Regulators of endocrine and metabolic rhythms. J Endocrinol 2007;195:187-98.

15. Johnston JD, Ordovás JM, Scheer FA, Turek FW. Circadian rhythms, metabolism, and chrononutrition in rodents and humans. Adv Nutr 2016;7:399-406

16. Reutrakul S, Knutson KL. Consequences of circadian disruption on cardiometabolic health. Sleep Med Clin 2015;10:455-68.

17. Unger T, Paulis L, Sica DA. Therapeutic perspectives in hypertension: Novel means for renin-angiotensin-aldosterone system modulation and emerging device-based approaches. Eur Heart J 2014;32:2739-47.

18. Gheorghiade M, Eichhorn EJ. Practical aspects of using beta-adrenergic blockade in systolic heart failure. Am J Med 2001;110 Suppl 7A:68S-73.

19. Tobe SW. Adrenergic receptor blockers in hypertension. Can J Cardiol 2014;30:S1-2.

20. McHugh J, Pokhrel P, Barber K, Liu G. Beta-blockers in the management of cardiovascular diseases. Osteopath Fam Physician 2010;2:131-8.

21. Cullington D, Yassin A, Cleland J. Beta-blockers in the treatment of cardiovascular disease. Prescriber 2008;19:31-9.

22. Eldrup-Jorgensen J. Measuring quality and the story of beta blockers. J Vasc Surg 2011;53:845-55.

23. Vardanyan R, Hruby V. Antihypertensive drugs. In: Synthesis of BestSeller Drugs. Amsterdam, Netherlands: Elsevier; 2016. p 331-2.

24. Charoenthai N, Wickramanayaka A, Sungthongjeen S, Puttipipatkhachorn S. Use of cassava starch nanocrystals to make a robust rupturable pulsatile release pellet. Drug Deliv Sci Technol 2018;47:283-90.
25. Davoodi P, Lee LY, Xu Q, Sunil V, Sun Y, Soh S, et al. Drug delivery systems for programmed and on-demand release. Adv Drug Deliv Rev 2018;132:104-38.

26. Bauskar MD, Nandedkar SY, Wagh RD. Formulation design and optimization of pulsatile release tablet of doxofylline with swelling and erodiable layers for treatment of nocturnal asthma. Int J Pharm Pharm Sci 2011;3 Suppl 5:218-23.

27. Domala R, Eedara BB, Dhurke RK. Development of pulsatile drug delivery system using novel solubilizers for antihypertensive drug. Int J Pharm Pharm Sci 2014;6:659-64

28. Jain D, Raturi R, Jain V, Bansal P, Singh R. Recent technologies in pulsatile drug delivery systems. Biomatter 2011;1:57-65.

29. Hardison S, Wan W, Dodson KM. The use of propranolol in the treatment of subglottic hemangiomas: A literature review and metaanalysis. Int J Pediatr Otorhinolaryngol 2016;90:175-80.

30. Bylund DB, Gruetter CA. Propranolol. In: Enna SJ, Bylund DB, editor. xPharm: The Comprehensive Pharmacology Reference. Boston, MA: Elsevier Inc.; 2007.

31. Lin-Wen L, Sheng-Feng H, Hong-Liang L, Hsiu OH, Ming-Thau S. Development of timely controlled-release systems for chronotherapy of propranolol with minimization of the $\mathrm{pH}$ Effect in the simulated gastrointestinal medium. J Food Drug Anal 2013;21:115-25.

32. Newton AM, Kaur B, Indana VL, Rajesh KS. Chronotherapeutic drug delivery of pectin Vs. Guar gum, xanthan gum controlled release colon targeted directly compressed propranolol $\mathrm{HCl}$ matrix tablets. SAJ Pharm Pharmacol 2014;1:201.

33. Gruetter CA. Metoprolol. In: Enna SJ, Bylund DB, editors. xPharm: The Comprehensive Pharmacology Reference. Boston: Elsevier; 2007. p. 1-7.

34. Borgaonkar PA, Bushetti SS, Najmuddin M. Formulation and evaluation of pulsatile drug delivery system of metoprolol tartarate using core in cup tablet. Am J Med Med Sci 2012;2:114-22.

35. Pavani D, Krishna EH, Ramesh S. Development and evaluation of metoprolol tartrate chronotherapeutic drug delivery system. J Innov Pharm Biol Sci 2015;2:53-63.

36. Vonica-Gligor AL, Tomuță I, Leucuța SE. Piecewise function parameters as responses of the design of experiment in the development of a pulsatile release chronopharmaceutical system. Acta Pharm 2016;66:173-89.

37. Emami J, Kazemali MR. Design and in vitro evaluation of a novel controlled onset extended-release delivery system of metoprolol tartrate. Res Pharm Sci 2016;11:81-92.

38. Salunkhe AK, Dias RJ, Mali KK, Mahajan NS, Ghorpade VS. Formulation and evaluation of floating pulsatile drug delivery system of metoprolol tartrate. Pharm Lett 2011;3:147-60.

39. Kumar KS, Kotaiah MR, Rao MP. Formulation and evaluation of pulsatile drug delivery system of metoprolol tartrate. Int J Pharm Res Biosci 2013;2:246-57

40. Agrawal SS, Dadarwal SC, Madan S. Formulation and in vitro characterization of chronopharmaceutical drug delivery system of metoprolol tartrate using hydroxypropyl cellulose. J Chronother Drug Deliv 2011;2:95-101

41. Taranalli SS, Dandagi PM, Mastiholimath VS. Development of hollow/ porous floating beads of metoprolol for pulsatile drug delivery. Eur J Drug Metab Pharmacokinet 2015;40:225-33.

42. Mishra A, Imam SS, Aqila M, Ahad A, Uzzafar A, Sultana Y, et al. Carvedilol nano lipid carrier: formulation, characterization and in-vivo evaluation. Drug Deliv 2016;23:1486-94.

43. Zhu LL, Zhou Q, Yan XF, Zeng S. Optimal time to take once-daily oral medications in clinical practice. Int J Clin Pract 2008;62:1560-71.

44. Aboud HM, Ali AA, El-Menshawe SF, Elbary AA. Nanotransfersomes of carvedilol for intranasal delivery: formulation, characterization and in vivo evaluation. Drug Deliv 2015;23:1-11.

45. Aggarwal V, Kumar R, Sharma R, Singh Y, Teotia UV. Formulation and optimization of chronotherapeutic drug delivery from carvedilol sulphate compression coated tablets by using design of experiment approach. J Appl Pharm Sci 2013;3:141-6.

46. Singh DK, Yadav SA, Nigade SU, Poddar S, Kumar S. Fabrication of pulsatile delivery multiparticulate system of poorly water soluble carvidolol phosphate. Int Res J Pharm 2012;3:235-40.

47. Satwara RS, Patel PK. Formulation and optimization of chronomodulated press-coated tablet of carvedilol by box-behnken statistical design. ChronoPhysiol Ther 2012;2:35-50.

48. Patel P, Dhake A. Design and development of colon specific microspheres for chronotherapy of hypertension. J Pharm Bioallied Sci 2012; 4:S33-4

49. Singh DK, Kumar S, Poddar S. Development of biphasic pulsatile 
release mini-tablets system of poorly water soluble carvedilol phosphate. Int J Pharm Sci Res 2015;6:919-26.

50. Ganipisetty VN, Jalandhar D, Gnanadev G, Manoj P, Nadh RV. Novel reversed phase liquid chromatographic method for the simultaneously determination of potential impurities of bisoprolol fumarate and hydrochlorothiazide in a fixed dosage form. Sep Sci Technol 2016;51:1362-9.

51. Rousan TA, Mathew ST, Thadani U. The risk of cardiovascular side effects with anti-anginal drugs. Expert Opin Drug Saf 2016;15:1609- 23.

52. Rosenberg J, Gustafsson F. Bisoprolol for congestive heart failure. Expert Opin Pharmacother 2008;9:293-300.

53. Jagdale SC, Bari NA, Kuchekar BS, Chabukswar AR. Optimization studies on compression coated floating-pulsatile drug delivery of bisoprolol. BioMed Res Int 2013;2013:801769.

54. Lund IT, Bøckmann PL, Jacobsen EE. Highly enantioselective CALBcatalyzed kinetic resolution of building blocks for $\beta$-blocker atenolol. Tetrahedron 2016;72:7288-92.

55. Kannappan V, Mannemala SS. Simultaneous enantioseparation and purity determination of chiral switches of amlodipine and atenolol by liquid chromatography. J Pharm Biomed Anal 2016;120:221-7.

56. Khataee A, Lotfi R, Hasanzadeh A, Iranifam M, Joo SW. Flowinjection chemiluminescence analysis for sensitive determination of atenolol using cadmium sulfide quantum dots. Spectrochim Acta 2016;157:88- 95

57. Amol M. Design and evaluation of pulsatile drug delivery system of atenolol for chronomodulated therapy. Int J Pharm Bio Sci 2012;3:1-8.

58. Keraliya RA, Patel MM. Effect of viscosity of hydrophilic coating polymer on lag time of atenolol pulsatile press coated tablets. J Pharm Chem 2014;1:15-21

59. Bonthagarala B, Vadrevu S, Nama S, Sudarshan D, Nuthakki S. Formulation and evaluation of pulsatile drug delivery system of atenolol. Am J Biol Pharm Res 2014;1:28-33.

60. Jagdale SC, Sali MS, Barhate AL, Kuchekar BS, Chabukswar AR. Formulation, development, and evaluation of floating pulsatile drug delivery system of atenolol. PDA J Pharm Sci Technol 2013;67:214-28.

61. Sumer F, Colakoglu MK, Ozdemir Y, Ozsay O, İlter O, Bostanci EB, et al. Effect of nebivolol on liver regeneration in an experimental $70 \%$ partial hepatectomy model. Asian J Surg 2017;40:375-9.

62. Kim YJ, Kim HR, Jeon HJ, Ju HJ, Chung S, Choi DE, et al. Rhabdomyolysis in a patient taking nebivolol. Kidney Res Clin Pract 2016;35:182-6.

63. Cockcroft J. Nebivolol: a review. Expert Opin Pharmacother 2004;5:893-9.

64. Er E, Elikkan HC, Erk N. Highly sensitive and selective electrochemical sensor based on high quality graphene/nafion nanocomposite for voltammetric determination of nebivolol. Sens Actuators B Chem 2015;224:170-7.

65. Nayak M, Patel U, Bhimani B, Patel G, Chaudhry S. Formulation and evaluation of pulsatile tablet of nebivolol for chronopharmacotherapy of hypertension. Int J Pharm Res Biosci 2015;4:388-401.

66. Sandhya P, Jagathi T. Formulation development and in vitro evaluation of pulsatile drug delivery system of nebivolol hydrochloride. J Pharm 2015;2:81-90.

67. Shivakumar K, Sharma JV, Devi AN. Formulation and in-vitro characterization of nebivolol pulsatile drug delivery system. J Glob Trends Pharm Sci 2014;5:2204-10.

68. Beckerman J. Heart Disease and Beta-Blocker Therapy 2016 WebMD, LLC. Available from: http://www.webmd.com/heart-disease/guide/ beta-blocker-therapy?print=true.

69. Hypertension (High Blood Pressure). U.S. National Library of Medicine. Rockville Pike, Bethesda: National Center for Biotechnology Information (NCBI). 